\title{
Mortalidad asociada con las temporadas de mayor circulación de los virus de la influenza en Bogotá, Colombia, 1997-2005
}

\author{
Alexandra Porras Ramírez, ${ }^{1}$ Alejandro Rico Mendoza, ${ }^{1}$ \\ José Moreno Montoya, ${ }^{1}$ Karol Cótes, ${ }^{1}$ Juan Diego López, ${ }^{2}$ \\ Diana Herrera, ${ }^{3}$ Gloria Rey ${ }^{3}$ y Fernando de la Hoz ${ }^{1}$
}

Forma de citar

Porras Ramírez A, Rico Mendoza A, Moreno Montoya J, Cótes K, López JD, Herrera D, et al. Mortalidad asociada con las temporadas de mayor circulación de los virus de la influenza en Bogotá, Colombia, 1997-2005. Rev Panam Salud Publica. 2009;26(5):435-9.

RESUMEN Objetivo. Estimar el exceso de mortalidad potencialmente atribuible a los virus de la influenza $A$ y $B$ y al virus sincitial respiratorio humano (VSRH) en las temporadas de mayor circulación de los virus de la influenza en Bogotá, Colombia entre 1997 y 2005.

Métodos. Se relacionaron las tasas mensuales de mortalidad general, por neumonía en menores de 5 años y por neumonía y afecciones cardiovasculares en mayores de 60 años, en Bogotá, Colombia, con las temporadas de mayor circulación de los virus de la influenza en esa ciudad. Los datos de mortalidad se obtuvieron del Departamento Nacional de Estadísticas de Colombia; las temporadas de mayor circulación de los virus se definieron como los meses contiguos en los que el número de aislamientos era igual o superior a la mitad del total de los aislamientos del año. Se calcularon las razones de tasas de incidencia (RTI) y sus intervalos de confianza de 95\% (IC95\%).

Resultados. El virus de la influenza A mostró un patrón de circulación estacional, pero no el de la influenza B y el VSRH. La mayor circulación de los virus de la influenza se asoció con un incremento promedio anual de $5 \%$ en la mortalidad general durante el período estudiado ( $R T I=1,05 ;$ IC95\%: 1,046 a 1,064). En las temporadas de mayor circulación de los virus de la influenza, la mortalidad combinada por neumonía e influenza en todas las edades fue mayor en $11 \%$ que en el resto del período (RTI =1,11; IC95\%: 1,051 a 1,178).

Conclusiones. En las temporadas de mayor circulación de los virus de la influenza en Colombia puede aumentar la mortalidad, en particular por neumonía y afecciones cardiovasculares en mayores de 60 años. Deben emprenderse acciones de prevención específicas para prevenir la influenza, especialmente en estos dos grupos de edad.

Palabras clave Virus de la influenza A; virus de la influenza B; virus sincitial respiratorio humano; variaciones estacionales; Colombia.

1 Universidad Nacional de Colombia, Santa Fe de Bogotá, Colombia. La correspondencia se debe dirigir a Alexandra Porras Ramírez, Universidad Nacional de Colombia, Carrera 45 No. 26-85, Edificio 471, Ciudad Universitaria, Bogotá, D.C., Colombia. Correo electrónico: porras.alexandra@ gmail.com

2 Secretaría Municipal de Salud de Manizales, Manizales, Caldas, Colombia.

3 Laboratorio de Virología, Instituto Nacional de Salud, Bogotá, Colombia.
Los virus de la influenza A y B son agentes patógenos de gran importancia para la salud pública, especialmente el de la influenza A ya que provoca grandes epidemias con una elevada mortalidad. Los brotes epidémicos causados por estos virus ocurren principalmente durante la estación invernal en los climas templados y de forma menos predecible en las regiones tropicales $(1,2)$. La estacionalidad de los virus de la influenza provoca un brusco aumento en la demanda de atención médica y sanitaria y en la mortalidad general y por algunas causas específicas en los meses de mayor circulación. Aunque este problema se ha estudiado ampliamente en los países templados, ha recibido mucha menos 
atención en los países ubicados en la zona intertropical.

Además de las afectaciones al sistema de salud, la influenza estacional tiene un gran costo para la economía de los países afectados y las familias debido al ausentismo laboral y escolar que provoca. Estudios recientes realizados en países templados indican que el costo total anual de los brotes de la influenza puede ser de 1 a 6 millones de dólares estadounidenses por 100000 habitantes (1-6).

Otro virus asociado con la aparición de brotes de infecciones respiratorias agudas es el virus sincitial respiratorio humano (VSRH), pero por lo general sus temporadas de mayor circulación no coinciden con la de los virus de la influenza.

En Colombia, un país sudamericano situado en la franja intertropical, el Instituto Nacional de Salud (INS) ha mantenido desde 1997 una vigilancia permanente de la circulación de los virus causantes de infecciones respiratorias agudas, mediante un esquema de recolección semanal de muestras en sitios centinelas. Como producto de esa vigilancia epidemiológica se ha recopilado la información necesaria para apoyar la toma de decisiones sobre la vacunación contra la influenza y se ha reunido un importante conjunto de datos que permite entender mejor el comportamiento de estos virus en áreas tropicales (7-11).

El objetivo del presente trabajo fue estimar el exceso de mortalidad potencialmente atribuible a los virus de la influenza A y B y al VSRH en las temporadas de mayor circulación de los virus de la influenza en Colombia entre 1997 y 2005.

\section{MATERIALES Y MÉTODOS}

Se realizó un estudio ecológico de tendencias temporales en el que las variables dependientes fueron las tasas mensuales de mortalidad general y por causas seleccionadas y la variable independiente fue la coincidencia o no con la temporada de mayor circulación de los virus de la influenza.

Se utilizaron los datos de 1997 a 2005 correspondientes a la ciudad de Bogotá, capital de Colombia, por ser el mayor centro económico y poblacional del país. Bogotá, con aproximadamente 8 millones de habitantes en su zona metropolitana (15\% de la población del país) (12), está situada en una meseta sobre la cor- dillera oriental de los Andes a 2640 metros sobre el nivel del mar y su temperatura promedio anual es de $14{ }^{\circ} \mathrm{C}$. A Bogotá corresponde más de $50 \%$ de los datos virológicos recopilados en el país y en esta ciudad se ha realizado en los últimos años un notable esfuerzo para mejorar la calidad de la vigilancia epidemiológica y reducir la mortalidad.

El INS estableció en 1997 una red de vigilancia centinela para los virus respiratorios. Desde enero de ese año, cada centro participante en el programa de vigilancia toma entre 5 y 10 muestras nasofaríngeas semanales de pacientes con síntomas de infección respiratoria aguda; en Bogotá se tomaron 8 muestras semanales en promedio durante $98 \%$ de las semanas de 1997 a 2005. Las muestras se analizaron en el Laboratorio de Virología del INS mediante técnicas de inmunofluorescencia indirecta y cultivo virológico; el control de la calidad del proceso y la identificación de la cepas de influenza se realizó en el Laboratorio de Influenza de los Centros para el Control y la Prevención de Enfermedades (CDC) de los Estados Unidos de América $(10,11)$.

Las temporadas de mayor circulación de los virus de la influenza y del VSRH se definieron como los meses contiguos en los que el número de aislamientos -independientemente de la cepa viral circulante - era igual o superior a la mitad del total de los aislamientos del año (cuadro 1). No se pudo definir una temporada de circulación de los virus de la influenza en el año 2001 debido al reducido número de aislamientos (8).

Los datos de mortalidad se obtuvieron del Departamento Nacional de Estadísticas de Colombia, agrupados por la causa básica de muerte según la Clasificación Internacional de Enfermedades, $10 .^{\mathrm{a}}$ revisión (CIE-10) (13). Se clasificaron como muertes por neumonía o influenza las correspondientes a los códigos J10 a J18 y por causas cardiovasculares las correspondientes a los códigos I210 a I269, I460 a I469, e I600 a I679.

Para identificar posibles patrones temporales en la circulación de los virus respiratorios estudiados a partir de las series mensuales utilizadas se evaluó el grado de asociación de los valores reales de la serie con los valores adyacentes (14) mediante la función de autocorrelación del programa informático Stata ${ }^{\circledR} \mathrm{v}$. 10.0. Los cálculos se hicieron de manera independiente para la circulación mensual de los virus de la influenza A y B y del VSRH.

CUADRO 1. Temporadas de mayor circulación de los virus de la influenza y el virus sincitial respiratorio humano en Colombia entre 1997 y 2005

\begin{tabular}{|c|c|c|c|}
\hline \multirow[b]{2}{*}{ Año } & \multicolumn{2}{|c|}{ Virus de la influenza A y B } & \multirow{2}{*}{$\begin{array}{c}\text { Virus sincitial } \\
\text { respiratorio humano } \\
\begin{array}{c}\text { Temporadas de } \\
\text { circulación }\end{array} \\
\end{array}$} \\
\hline & $\begin{array}{l}\text { Temporadas de } \\
\text { circulación }\end{array}$ & Subtipo de virus & \\
\hline 1997 & Septiembre-octubre & $\begin{array}{l}\text { Influenza A H3N2 Sydney } \\
\text { Influenza B Beijing }\end{array}$ & Marzo-mayo \\
\hline 1998 & Septiembre-noviembre & Influenza A H3N2 Sydney & Abril-mayo \\
\hline 1999 & Junio-diciembre & $\begin{array}{l}\text { Influenza A H3N2 Sydney } \\
\text { Influenza A H3N2 Panamá } \\
\text { Influenza B Beijing } \\
\text { Influenza B Sichuán }\end{array}$ & Marzo-mayo \\
\hline 2000 & Abril-junio & $\begin{array}{l}\text { Influenza A H3N2 Panamá } \\
\text { Influenza A H1N1 Johannesburg }\end{array}$ & Julio-diciembre \\
\hline 2001 & $\mathrm{ND}^{\mathrm{a}}$ & & Marzo-abril \\
\hline 2002 & Julio-octubre & $\begin{array}{l}\text { Influenza A H1N1 Nueva Caledonia } \\
\text { Influenza A H3N2 Panamá } \\
\text { Influenza B Brisbane } \\
\text { Influenza B Sichuán }\end{array}$ & Mayo-junio \\
\hline 2003 & Octubre-diciembre & $\begin{array}{l}\text { Influenza A H3N2 Panamá } \\
\text { Influenza A H3N2 Wyoming } \\
\text { Influenza A H3N2 Fujian } \\
\text { Influenza A H3N2 Corea } \\
\text { Influenza B South Carolina }\end{array}$ & Abril-julio \\
\hline 2004 & Mayo-noviembre & $\begin{array}{l}\text { Influenza A H3N2 Wyoming } \\
\text { Influenza B Hawai }\end{array}$ & Mayo-julio \\
\hline 2005 & Septiembre-noviembre & $\begin{array}{l}\text { Influenza A H3N2 Wisconsin } \\
\text { Influenza B Shangai }\end{array}$ & Abril-junio \\
\hline
\end{tabular}

${ }^{a}$ ND: no se pudo definir una temporada de circulación de los virus de la influenza en el año 2001 debido al reducido número de aislamientos (8). 
Se calcularon las tasas de mortalidad general, por neumonía, neumonía más influenza y afecciones cardiovasculares para cada mes entre 1997 y 2005. Con esos datos se estimaron las tasas promedio de mortalidad para los meses con mayor circulación de los virus de la influenza y el resto del año. Se calcularon las razones de las tasas de incidencia (RTI) y sus intervalos de confianza de 95\% (IC95\%). Se utilizó la regresión de Poisson para estimar la magnitud de la asociación entre la mortalidad y la circulación de los virus estudiados para todo el período 1997-2005.

Debido a las particularidades de la mortalidad por infecciones respiratorias agudas, se realizaron análisis por separado para menores de 5 años (mortalidad general y por neumonía) y mayores de 60 años (mortalidad general, por neumonía y afecciones cardiovasculares).

\section{RESULTADOS}

Se encontró asociación entre los meses de mayor número de muestras positivas del virus de la influenza A y los meses adyacentes en un patrón que indica que existe una periodicidad estacional de alrededor de 12 meses en la circulación de este virus.

Sin embargo, el análisis de correlación mostró que no existe una tendencia estacional en la circulación del virus de la influenza B y el VSRH.

En siete de los nueve años estudiados se observó un aumento en las tasas de mortalidad general durante los meses de mayor circulación de los virus de la influenza que en el resto del año, pero este efecto fue estadísticamente significativo solamente en los años 1998 y 2003. Sin embargo, la circulación de estos virus se asoció con un incremento promedio anual de 5\% en la mortalidad general durante todo el período estudiado $(\mathrm{RTI}=$ 1,05; IC95\%: 1,046 a 1,064) (cuadro 2).

La mortalidad combinada por neumonía e influenza en todas las edades fue $11,0 \%$ mayor en las temporadas de mayor circulación de los virus de la influenza con respecto al resto del período $(\mathrm{RTI}=1,11$; IC95\%: 1,051 a 1,178; $P<0,01)$. Esta relación se observó por separado en las temporadas de mayor circulación de los virus de la influenza con respecto al resto del año en siete de los nueve años estudiados, pero solo fue estadísticamente significativa en el año 2000 (con una diferencia entre las tasas de 5,4 por 10000 habitantes; $P<0,01$ ). Al combinar la experiencia de los nueve años mediante la regresión de Poisson, se observó que las tasas de mortalidad por estas causas aumentaron en promedio $6 \%$ en los meses de mayor circulación de los virus de la influenza (RTI = 1,06; IC95\%: 1,021 a 1,120) con respecto al resto del período.

La mortalidad por afecciones cardiovasculares en los mayores de 60 años también aumentó durante las temporadas de mayor circulación de los virus de la influenza con respecto al resto del año. Este aumento fue estadísticamente significativo para los años 1998 y 2003, con diferencias entre las tasas de 8,2 por 10000 habitantes $(P<0,05)$ y 10,0 por 10000 habitantes $(P<0,001)$, respectivamente. En promedio, las tasas de mortalidad por esta causa se incrementaron en $8,0 \%$ du- rante los meses de mayor circulación de los virus de la influenza $(\mathrm{RTI}=1,08$; IC95\%: 1,06 a 1,11).

En menores de 5 años se observó un aumento en la mortalidad por neumonía durante las temporadas de mayor circulación de los virus de la influenza en los años 2000, 2003, 2004 y 2005, pero estas diferencias no fueron significativas $(P>0,05)$. Tampoco se encontró un aumento significativo en las tasas de mortalidad por neumonía durante esas temporadas con respecto al resto del período (RTI = 1,07; IC95\%: 0,97 a 1,17).

En los mayores de 60 años se observó un exceso significativo de muertes por neumonía en los años 1997, 2002 y 2005 $(P<0,05)$. En promedio, en las temporadas de mayor circulación de los virus de la influenza, la mortalidad por neumonía aumentó en 10,0\% (RTI $=1,10$; IC95\%: 1,041 a 1,178) (cuadro 2).

\section{DISCUSIÓN}

El patrón estacional de circulación del virus de la influenza A encontrado en Colombia no se había descrito con anterioridad. Los brotes de influenza A se presentan con intervalos aproximados de 1 año (de 50 a 52 semanas), con picos máximos entre septiembre y noviembre y solo en el año 2000 predominaron los aislamientos de este virus durante los meses de abril, mayo y junio. El predominio de la circulación viral en el segundo semestre puede estar asociado con el período de lluvias intensas en Bogotá, que generalmente es de octubre a noviembre (8). Este comportamiento difiere del observado en la circulación del

CUADRO 2. Tasas de mortalidad ${ }^{\mathrm{a}}$ general, por neumonía y afecciones cardiovasculares, según las temporadas de mayor o menor circulación de los virus de la influenza en Bogotá entre 1997 y 2005

\begin{tabular}{|c|c|c|c|c|c|c|c|c|c|}
\hline \multirow[b]{2}{*}{ Año } & \multicolumn{3}{|c|}{ Tasa de mortalidad general } & \multicolumn{3}{|c|}{$\begin{array}{l}\text { Tasa de mortalidad por neumonía } \\
\text { en mayores de } 60 \text { años }\end{array}$} & \multicolumn{3}{|c|}{$\begin{array}{l}\text { Tasa de mortalidad por enfermedad } \\
\text { cardiovascular en mayores de } 60 \text { años }\end{array}$} \\
\hline & $\begin{array}{c}\text { En temporadas } \\
\text { de mayor } \\
\text { circulación }\end{array}$ & $\begin{array}{l}\text { Resto } \\
\text { del año }\end{array}$ & Diferencia & $\begin{array}{c}\text { En temporadas } \\
\text { de mayor } \\
\text { circulación }\end{array}$ & $\begin{array}{l}\text { Resto } \\
\text { del año }\end{array}$ & Diferencia & $\begin{array}{l}\text { En temporadas } \\
\text { de mayor } \\
\text { circulación }\end{array}$ & $\begin{array}{l}\text { Resto } \\
\text { del año }\end{array}$ & Diferencia \\
\hline 1997 & 452,28 & 445,56 & 6,72 & 170,30 & 133,55 & $36,75^{b}$ & 590,07 & 540,27 & 49,80 \\
\hline 1998 & 457,05 & 427,45 & $29,6^{b}$ & 126,07 & 116,05 & 10,02 & 912,56 & 818,21 & $94,35^{b}$ \\
\hline 1999 & 462,82 & 441,35 & 21,47 & 87,87 & 119,82 & $-31,95$ & 827,67 & 957,51 & $-129,84$ \\
\hline 2000 & 397,54 & 379,89 & 17,65 & 111,46 & 117,60 & $-6,14$ & 1643,01 & 1504,21 & $138,89^{b}$ \\
\hline 2002 & 435,14 & 423,61 & 11,53 & 127,60 & 100,09 & $27,51^{b}$ & 1245,54 & 1231,72 & 13,82 \\
\hline 2003 & 462,69 & 415,23 & $47,46^{d}$ & 140,78 & 130,38 & 10,4 & 1136,82 & 1191,34 & $-54,52$ \\
\hline 2004 & 421,27 & 423,38 & $-2,11$ & 84,81 & 110,50 & $-25,69$ & 1116,72 & 985,92 & $130,80^{c}$ \\
\hline 2005 & 359,44 & 351,11 & 8,33 & 160,74 & 118,88 & $41,86^{b}$ & 2654,73 & 1000,73 & $1654,00^{d}$ \\
\hline
\end{tabular}

Tasas de mortalidad por 10000 habitantes.

${ }^{b}$ Diferencia significativa según el estadístico de Wald de la regresión de Poisson, $P<0,05$.

${ }^{\mathrm{C}}$ Diferencia significativa según el estadístico de Wald de la regresión de Poisson, $P<0,01$.

${ }^{d}$ Diferencia significativa según el estadístico de Wald de la regresión de Poisson, $P<0,001$. 
virus de la influenza B y del VSRH, que no mostraron un patrón estacional definido. Esto último apoya la idea de que, pese al bajo número de muestras tomadas durante la vigilancia centinela de los virus respiratorios durante el período de estudio, la detección de la estacionalidad del virus de la influenza A no se vio afectada por un sesgo de mala clasificación (15-19).

Los picos de influenza en los países tropicales muestran una amplia variabilidad (20). En un estudio de 12 años realizado en la India se encontró que el pico de aislamientos ocurría entre julio y septiembre, con una mayor frecuencia en julio, lo que coincidía con la temporada de lluvias $(18,21)$. En Brasil, la estacionalidad de la influenza también coincide con la estación de lluvia en las diferentes regiones del país, con un pico de actividad de influenza entre mayo y octubre en el sudeste y de noviembre a mayo en el norte (18). El patrón encontrado en Colombia en el presente estudio se ubica entre esos dos patrones, con el pico más alto de actividad entre septiembre y octubre y un pico menor entre abril y mayo.

Además, en el presente estudio se identificó una asociación empírica estadísticamente significativa entre la mayor circulación de los virus de la influenza y el aumento en la mortalidad general y por neumonía combinada con influenza en todas las edades, así como por neumonía y afecciones cardiovasculares en mayores de 60 años. Aunque estas asociaciones no fueron significativas todos los años analizados en forma individual, sí lo fue para el total del período tomado en conjunto. En algunos años, la asociación entre la mortalidad y la circulación de los virus de la influenza fue más fuerte que el promedio para el período. Esta variabilidad puede estar relacionada con los tipos de virus que circularon durante el período; por ejemplo, durante la temporada de 2003 circularon predominantemente tres cepas del virus de la influenza A H3N2, de mayor virulencia y letalidad $(22,23)$, lo que puede haberse reflejado en una mayor mortalidad por todas las causas en todas las edades. Ese año, los servicios de salud detectaron un aumento en el número de casos graves de enfermedades respiratorias en jóvenes, con una alta letalidad.

A partir de estos resultados, se estima que en promedio se producirían 1400 muertes anuales por el virus de la influenza A en la ciudad de Bogotá, de las cuales 70 serían por neumonía en menores de 5 años y más de 600 por afecciones cardiovasculares en mayores de 60 años. Estas muertes representan aproximadamente $5 \%$ de las defunciones anuales por todas las causas en todos los grupos de edad en Bogotá.

La relación entre la circulación de los virus de la influenza y el aumento en la mortalidad se ha demostrado ampliamente en los países templados, tanto desarrollados como en vías de desarrollo, aunque no se cuenta con suficientes datos de las zonas intertropicales, en particular de América Central y América del Sur (22-24). En un estudio realizado en Singapur, una ciudad intertropical, se encontró que la circulación de los virus de la influenza estaba asociada con aumentos de $1 \%$ a $13 \%$ en la mortalidad por todas las causas, neumonía y afecciones cardiovasculares entre $1996 \mathrm{y}$ 2003 (25). Esos datos coinciden ampliamente con lo encontrado en el presente estudio en Colombia.

No haber observado un exceso de muertes por neumonía en menores de 5 años puede deberse a varias limitaciones del presente estudio, entre ellas la posible mala clasificación en la definición de las temporadas de influenza debido al reducido número de muestras tomadas cada semana. Es posible que algunas semanas pertenecientes a la temporada de influenza hayan quedado clasificadas como fuera de temporada o viceversa, lo que llevaría a un sesgo de mala clasificación no diferencial que afectaría a la significación de la asociación entre la circulación de los virus de la influenza y la mortalidad. Debido al escaso número de muertes por neumonía en comparación con el total, este tipo de error podría ocultar una posible asociación significativa. Otra fuente de error podría estar en la posible mala clasificación de las causas de muerte por neumonía, lo que también llevaría a disminuir artificialmente la magnitud de la asociación.

La circulación de otros virus respiratorios puede también haber influido negativamente sobre la asociación entre la mortalidad por neumonía y el nivel de circulación de los virus de la influenza. Sin embargo, como se puede observar en el cuadro 1, solamente en mayo de 2004 coincidieron las temporadas de circulación del VSRH y los virus de la influenza. A pesar de que todos los resultados obtenidos ese año se ajustaron, no hubo diferencias con respecto a los resultados antes de ajustar. No obstante, por las mismas razones esgrimidas más arriba, no se puede excluir completamente la posibilidad de que el efecto de otros virus respiratorios pueda haber influido negativamente en las asociaciones analizadas.

En conclusión, los resultados del presente estudio indican que en las temporadas de mayor circulación de los virus de la influenza en Colombia puede aumentar la mortalidad, en particular por neumonía y afecciones cardiovasculares en mayores de 60 años.

En la actualidad, el Ministerio de la Protección Social de Colombia provee la vacuna contra la influenza estacional a los menores de 2 años, pero no a los mayores de 60 años. Se recomienda establecer un programa de vacunación a adultos mayores a fin de evitar un número considerable de muertes cada año en ese sensible grupo de la población.

Agradecimientos. Al Instituto Nacional de Salud por su apoyo para la realización de este estudio y al Ministerio de la Protección Social de Colombia por su apoyo y el financiamiento otorgado dentro del Plan de Preparación para la Pandemia de Influenza.

\section{REFERENCIAS}

1. Organización Mundial de la Salud. Vacunas contra la influenza. Bol Epidemiol Semanal. 2005;80(33):279-328.

2. Organización Panamericana de la Salud. Prevención y control de la influenza. Rev Panam Salud Publica. 2002;12(1):63-70.
3. Louie J, Schechter R, Honarmand S, Guevara HF, Shoemaker TR, Madrigal NY, et al. Severe pediatric influenza in California, 2003-2005: implications for immunization recommendations. Pediatrics. 2006;117(4): e610-8.
4. Bridges CB, Harper SA, Fukuda K, Uyeki TM, Cox NJ, Singleton JA, Advisory Committee on Immunization Practices. Prevention and control of influenza: recommendations of the Advisory Committee on Immunization Prac- 
tices (ACIP). MMWR Recomm Rep. 2003;52 (RR-8):1-34.

5. Gardner P, Schaffner W. Immunization of adults. N Engl J Med. 1993;328:1252-8.

6. Sox HC. Preventive health services in adults. N Engl J Med. 1994;330:1589-95.

7. República de Colombia, Instituto Nacional de Salud. Epidemia de influenza A/H3N2 en Colombia 1996: actualización. Inf Quincenal Epidemiol Nac. 1996;1(3):39-41.

8. Herrera-Rodríguez DH, de la Hoz F, Mariño C, Ramírez E. Respiratory virus in children aged less than 10 years old suffering from respiratory infection in the Hospital Militar Central in Bogota from 2000-2001. Rev Salud Publica. 2007;9(4):576-86.

9. Herrera-Rodríguez DH, de la Hoz F, Mariño C, Ramírez E, López JD, Vélez C. Adenovirus in children under five years of age. Circulation patterns and clinical and epidemiological characteristics in Colombia, 1997-2003. Rev Salud Publica. 2007:9(3):420-9.

10. Herrera D, de la Hoz F, Velandia M. Severe respiratory disease and its relationship with respiratory viruses in Colombia. Int J Infect Dis. 2008;12(2):139-42.

11. República de Colombia, Ministerio de Salud. Vigilancia epidemiológica para influenza y otros virus respiratorios. Inf Quincenal Epidemiol Nac. 1998;3(1):1-6.
12. Departamento Administrativo Nacional de Estadística. Censo General 2005. Nivel nacional. Santa Fe de Bogotá: DANE; 2005.

13. Organización Panamericana de la Salud. Clasificación estadística internacional de enfermedades y problemas relacionados con la salud. 10. ${ }^{a}$ revisión. Vol. 1-3. Washington, D.C.: OPS; 2003. (Publicación científica No. 554.)

14. Chatfield C. The analysis of time series: an introduction. London: Chapman and Hall; 2003.

15. Chiu S, Lung Y, Chan KH, Wong WHS, Peiris M. Influenza-related hospitalizations among children en Hong Kong. N Engl J Med. 2002; 347:2097-103.

16. Abarca KV. Influenza: vacunación a nuevos grupos etarios. Rev Chil Infectologia. 2007; 24(3):227-30.

17. Monto A. Global burden of influenza: what we know and what we need to know. Int Congr Ser. 2004;1263:3-11.

18. Shek LP, Lee BW. Epidemiology and seasonality of respiratory tract infections in the tropics. Paedtr Respir Rev. 2003;4:105-11.

19. Rao B, Kanerje K. Influenza surveillance in Pune, India, 1978-1990. Bull World Health Org. 1993;71(2):177-81.

20. Viboud C, Alonso V, Simonsen L. Influenza in tropical regions. PLoS Med. 2006;3(4):e89.
21. Alonso W, Viboud C, Simonsen L, Hirano E, Daufenbach L, Miller M. Seasonality of influenza in Brazil: a travelling wave from the Amazon to the subtropics. Am J Epidemiol. 2007;165:1434-42.

22. Kuszniers G, Imaz S, Zerbini E, Savy V, Knez $V$, Sequeira M. Efecto de las epidemias de influenza sobre la mortalidad en Santa Fe, Argentina, en 1992-1999. Rev Panam Salud Publica. 2002;12(1):26-36

23. Thompson WW, Shay DK, Weintraub E, Brammer L, Cox NJ, Anderson LJ, et al. Mortality associated with influenza and respiratory syncytial virus in the United States. J Am Med Assoc. 2003;289:179-85.

24. Fleming DM, Pannell RS, Elliot AJ, Cross KW. Respiratory illness associated with influenza and respiratory syncytial virus infection. Arch Dis Child. 2005;90:741-6.

25. Chow A, Ma S, Ling A, Chew S. Influenza associated deaths in tropical Singapore. Emerg Infect Dis. 2006;12(1):114-21.

Manuscrito recibido el 20 de septiembre de 2008. Aceptado para publicación, tras revisión, el 19 de abril de 2009.

ABSTRACT Objective. To estimate potential excess mortality attributable to influenza viruses A and B and human respiratory syncytial virus (HRSV) during peak seasons of influenza virus circulation in Colombia from 1997 to 2005.

Mortality associated with peak seasons of influenza virus circulation in Bogotá, Colombia, 1997-2005

Key words
Methods. A comparison of monthly, general mortality rates from pneumonia in children under 5 years of age and from pneumonia and cardiovascular disease in those more than 60 years of age in Bogota, Colombia, were compared to the city's peak seasons of influenza virus circulation. Mortality data were obtained from the National Bureau of Statistics of Colombia; peak seasons of virus circulation were defined as contiguous months in which the number of isolates was equal to or greater than half the total number of isolates for the year. Incidence rate ratios (IRR) and their $95 \%$ confidence intervals $(95 \% \mathrm{CI})$ were determined.

Results. Influenza A demonstrated a pattern of seasonal circulation, but influenza B and HRSV did not. The increased circulation of influenza virus was associated with an average annual increase of $5 \%$ in overall mortality during the study period (IRR $=1.05 ; 95 \%$ CI: $1.046-1.064)$. During seasons of increased circulation of influenza viruses, the combined mortality from pneumonia and influenza for all ages was $11 \%$ higher than it was at other times (IRR $=1.11$; 95\%CI: 1.051-1.178).

Conclusions. During peak seasons of influenza virus circulation in Colombia, there can be increased mortality, particularly from pneumonia and cardiovascular disease among those more than 60 years of age. Preventive actions specific to protecting against influenza should be taken, especially in these two age groups.

Influenza A virus; influenza B virus; respiratory syncytial virus, human; seasonal variations; Colombia. 